DOI https://doi.org/10.30525/978-9934-588-81-5-2.40

\title{
PSEUDOMONADACEAE AS VANCOMYCIN RESISTANCE GENE RESERVOIR IN PATIENTS WITH CYSTIC FIBROSIS
}

\author{
Tymchuk I. V. \\ Doctor of Philosophy (Medical Sciences), Associate Professor, \\ Associate Professor at the Department of Microbiology \\ Danylo Halytskyi Lviv National Medical University \\ Panas M. A. \\ Doctor of Philosophy (Medical Sciences), Associate Professor, \\ Associate Professor at the Department of Microbiology \\ Danylo Halytskyi Lviv National Medical University \\ Konechnyi Yu. T. \\ Graduate Student at the Department of Microbiology \\ Danylo Halytskyi Lviv National Medical University \\ Korniychuk O. P. \\ Doctor of Medical Sciences, Professor, \\ Head of the Department of Microbiology \\ Danylo Halytskyi Lviv National Medical University \\ Danyleichenko V. V. \\ Doctor of Medical Sciences, Professor, \\ Professor at the Department of Microbiology \\ Danylo Halytskyi Lviv National Medical University \\ Lviv, Ukraine
}

Cystic fibrosis is a serious genetic disease accompanied by chronic respiratory infections and damage to other organs. Bacteria of the Pseudomonas and Staphylococcus genera are mainly their etiological factor. When methicillin-resistant staphylococci are isolated, the reserve drug for such patients is vancomycin. Pseudomonadaceae are naturally resistant to vancomycin because their outer membrane is a barrier to large glycopeptide molecules. However, under certain conditions, the possibility of acquiring vancomycin resistance genes is not excluded.

The objective of the study was to search for vancomycin resistance genes in Pseudomonadaceae isolated from patients with cystic fibrosis.

Five strains of Pseudomonas aeruginosa with multiple resistance isolated from the sputum of patients with cystic fibrosis were selected for the 
study. The material was seeded on CHROMID ${ }^{\circledR}$ P. aeruginosa Agar bioMérieux to isolate Pseudomonadaceae. Identification was performed using NEFERMtest 24 Lachema. Antibiotic sensitivity was determined using the Kirby-Bauer method. Total DNA was isolated from a pure Pseudomonadaceae culture. Vancomycin resistance Van A and Van B genes were determined by PCR. Primers used for PCR detection of genes encoding vancomycin resistance Van AF (5'-GGGAAAACGACAATTTGC-3') \& Van AR (5'-GTACAATGCGGCCGTTA-3') amplicon size 732 bp, Van BF (5'-CATCGCCGTCCCCGAATTTCAAA-3') \& Van BR (5' GATGCGGAAGATACCGTGGCT-3') amplicon size 297 bp.

Isolated microorganisms identified as $P$. aeruginosa were selected for research in the presence of phenotypic resistance to more than three groups of antibiotics, including the glycopeptide vancomycin and teicoplanin antibiotics. The Vancomycin resistance gene Van A was detected in all studied $P$. aeruginosa strains and two strains possessed the Van A and Van B genes, which made $40 \%$. Since these genes are localized in plasmids, it is possible to transfer these genes to other microorganisms, in particular, $S$. aureus, that will create a problem during antibiotic treatment.

Studies showed that Pseudomonadaceae can be carriers of vancomycin resistance genes, as previously reported. The future direction of the study is to conduct experiments to confirm interspecies transmission of vancomycin resistance genes between $P$. aeruginosa and $S$. aureus. 